Table 6. Hydrogen-bonding distances and angles in 1,6-anhydro- $\beta$-D-mannofuranose

\begin{tabular}{|c|c|c|c|}
\hline$k$ & $D_{J k}$ & $D_{i k}$ & $\angle i j k$ \\
\hline $\mathrm{O}(2 a)-\mathrm{H}(\mathrm{O} 2 a)-\mathrm{O}(4 e)$ & $2.05 \AA$ & $2 \cdot 818 \AA$ & $134^{\circ}$ \\
\hline$-\mathrm{O}(5 e)$ & $2 \cdot 29$ & $3 \cdot 140$ & 146 \\
\hline $\mathrm{O}(3 a)-\mathrm{H}(\mathrm{O} 3 a)-\mathrm{O}(1 b)$ & $2 \cdot 04$ & 2.859 & 169 \\
\hline $\mathrm{O}(5 a)-\mathrm{H}(\mathrm{O} 5 a)-\mathrm{O}$ & $2 \cdot 23$ & $2 \cdot 934$ & 145 \\
\hline$-\mathrm{O}$ & $2 \cdot 31$ & 2.997 & 143 \\
\hline
\end{tabular}

Non-bonded $\mathrm{O} \cdots \mathrm{O}$ distances less than $3.3 \AA$

$\begin{array}{ll}\mathrm{O}(1 a) \cdots \mathrm{O}(2 a) & 2 \cdot 832 \AA \\ \mathrm{O}(1 a) \cdots \mathrm{O}(4 a) & 2 \cdot 318 \\ \mathrm{O}(1 a) \cdots \mathrm{O}(5 a) & 3 \cdot 095 \\ \mathrm{O}(2 a) \cdots \mathrm{O}(3 a) & 2 \cdot 650 \\ \mathrm{O}(2 a) \cdots \mathrm{O}(5 g) & 2 \cdot 934 \\ \mathrm{O}(4 a) \cdots \mathrm{O}(5 a) & 2 \cdot 776\end{array}$

Symmetry code

$\begin{array}{rrrr}a & x & y & z \\ b & -\frac{1}{2}-x & 1-y & -\frac{1}{2}+z \\ c & -\frac{1}{2}-x & 1-y & \frac{1}{2}+z \\ d & -1-x & -\frac{1}{2}+y & \frac{1}{2}-z \\ e & -1-x & \frac{1}{2}+y & \frac{1}{2}-z \\ f & -x & -\frac{1}{2}+y & \frac{1}{2}-z \\ g & -x & \frac{1}{2}+y & \frac{1}{2}-z \\ h & -\frac{1}{2}+x & \frac{1}{2}-y & 1-z \\ i & \frac{1}{2}+x & \frac{1}{2}-y & 1-z\end{array}$

This research was supported in part by the U.S. Public Health Service, National Institutes of Health
Grant No. GM-11293, and in part by the National Science Foundation, University Science Development Grant No. GU-3184.

\section{References}

Berking, B. \& Seeman, N. C. (1971). Acta Cryst. B27, 1752.

Berman, H. M., Chu, S. C. \& Jeffrey, G. A. (1967). Science, 157, 1576.

Brown, G. M. \& Thiessen, W. E. (1969). Acta Cryst. A25, S 195.

Cromer, D. T. \& Waber, J. T. (1965). Acta Cryst. 18, 104.

Heyns, K., Köll, P. \& Paulsen, H. (1971). Chem. Ber. 104,830 .

Hoog, A. J. De, Buys, H. R., Altona, C. \& Havinga, E. (1969). Tetrahedron, 25, 3365.

Jefrerey, G. A., Pople, J. A. \& Radom, L. (1972). Carbohydr. Res. Submitted for publication.

JoHNSON, C. K. (1965). ORTEP. Report ORNL-3794, Oak Ridge National Laboratory, Oak Ridge, Tennessee.

Park, Y. J., Kim, H. S. \& JefFrey, G. A. (1971). Acta Cryst. B27, 220.

Radom, L., Hehre, W. J. \& Pople, J. A. (1971). J. Amer. Chem. Soc. 93, 289.

Stewart, R. F., Davidson, E. R. \& Simpson, W. T. (1965). J. Chem. Phys. 42, 3175.

Acta Cryst. (1972). B28, 3415

\title{
The Crystal and Molecular Structure of 2,3-Diazanaphthalene
}

\author{
By C.Huiszoon, B. W.van de WaAl, A.B.van Egmond and S. Harkema \\ Chemical Physics Laboratory, Twente University of Technology, P.O. Box 217, Enschede, The Netherlands
}

(Received 20 April 1972)

The structure of 2,3-diazanaphthalene (phthalazine) has been determined by X-ray methods. Cell constants and intensity data were obtained with a single-crystal diffractometer. The space group is $P b c a$. Cell constants are $13.695,10.557$ and $9.285 \AA$. There are eight nearly planar molecules in the unit cell.

\section{Introduction}

In our laboratory research is carried out on the chemical and physical properties of diazanaphthalenes. Topics included so far are electron spin resonance (van den Ham, du Sart \& van der Meer, 1971) and photoelectron spectra (van den Ham \& van der Meer, 1972). In the course of these investigations the determination of the structures of the diazanaphthalenes seemed worth while. Moreover the crystal structure may be of interest from a lattice-dynamical point of view.

Of the anhydrous diazanaphthalenes, the crystal and molecular structure of 1,8-diazanaphthalene has been determined by Clearfield, Sims \& Singh (1972). The structures of the dihydrates of 1,5-diazanaphthalene (orthorhombic form) and 2,6-diazanaphthalene have been solved by Brufani, Duranti, Giacomello \& Zambonelli (1961) and by Brufani, Fedeli, Giacomello, Riccieri \& Vaciago (1966) respectively. In the present paper the crystal and molecular structure of 2,3-diazanaphthalene or phthalazine is described.

\section{Experimental}

Small single crystals with linear dimensions of about $0.4 \mathrm{~mm}$ were grown by slow sublimation in vacuum 
$\left(0.5\right.$ Tor) at about $35^{\circ} \mathrm{C}$. The density of the crystals was determined by a pycnometric method. The dimensions of the orthorhombic unit cell were obtained from a single crystal mounted on a three circle diffractometer, with $\mathrm{Ni}$-filtered $\mathrm{Cu} K \alpha$ radiation.

\section{Crystal data}

Crystal system: orthorhombic;

$a=13.695(5), b=10.557(5), c=9 \cdot 285(5) \AA$ at $20^{\circ} \mathrm{C}$. Space group: $\mathrm{Pbca}$ (from the systematic absences:

$h k 0$ with $k$ odd, $h 0 l$ with $l$ odd and $0 k l$ with $k$ odd). Observed density: 1.279 g.cm ${ }^{-3}$ at $23^{\circ} \mathrm{C}$.

Calculated density with 8 molecules in the unit cell: 1.279 g.cm ${ }^{-3}$.

Calculated linear absorption coefficient: $0.87 \mathrm{~cm}^{-1}$

(Mo $K \alpha$ radiation).

The crystal (maximum dimension $0.4 \mathrm{~mm}$ ) was mounted in a Lindemann-glass capillary tube with the reciprocal $[01 \overline{1}]$ axis parallel to the spindle axis of the goniometer. Intensity data were collected on an automatic three-circle diffractometer using $\mathrm{Zr}$-filtered Mo $K \alpha$ radiation. The temperature was kept at $20^{\circ} \mathrm{C}$. Intensities were measured with a $\theta / 2 \theta$ scan at the rate of $0.6^{\circ}$ per min with stationary background counting. The scan angle was kept at $1^{\circ}$. Reflexions $h k l$ and $h k l$ were measured for $\theta$ values up to $25^{\circ} .925$ reflexions in the range had an intensity greater than twice the standard deviation as estimated from counting statistics. The number of independent reflexions was 703 . No change in standard reflexions was observed during the measurements.

\section{Structure determination and refinement}

Two methods have been applied independently to determine the structure:

(a) A least-squares packing analysis was performed, employing the program PCK5 (Williams, 1969). Upon varying the three rotational and the three translational parameters defining the position of a molecule of assumed shape in the asymmetric unit of the unit cell, 26 minima were found in the repulsive potential energy surface. For 7 minima the repulsive part of the lattice energy was less than $1.0 \mathrm{kcal}^{\mathrm{m} m o l{ }^{-1}}$. Atomic coordinates corresponding to these minima were used in the least-squares fitting program for calculated and observed intensities, ORFLS (Busing, Martin \& Levy, 1962). The repulsive energy of the minimum leading to the correct structure was $0.66 \mathrm{kcal}^{\mathrm{mole}} \mathrm{m}^{-1}$. Only one minimum was found with a lower energy: 0.60 kcal.mole ${ }^{-1}$. The expression for the interatomic nonbonded potential repulsive energy was (Williams, 1969):

$$
E_{\mathrm{r}}=w_{i j}\left(r_{i j}^{(0)}-r_{i j}\right)^{2}, \quad r_{i j}<r_{i j}^{(0)} ; \quad E_{\mathrm{r}}=0, \quad r_{i j}>r_{i j}^{(0)},
$$

where $r_{i j}^{(0)}$ is an empirical constant, $r_{i j}$ an interatomic distance, $w_{i j}$ a scaling factor. The parameters $w_{i j}$ and $r_{i j}^{(0)}$ are listed in Table 1.
Table 1. Parameters used for the calculation of the nonbonded potential repulsive energy

$\begin{array}{ccc}i j & w_{i j}\left(\mathrm{kcal}^{\mathrm{mol}} \mathrm{mol}^{-1} \AA^{-2}\right) & r_{i j}^{(0)}(\AA) \\ \mathrm{HH} & 0.93 & 2.829 \\ \mathrm{HC} & 0.87 & 3.157 \\ \text { HN } & 0.82 & 3.209 \\ \mathrm{CC} & 0.88 & 3.440 \\ \text { CN } & 0.81 & 3.489 \\ \text { NN } & 0.73 & 3.543\end{array}$

The parameters have been obtained from a leastsquares fit to the repulsive part of the non-bonded potential functions reported by Bartell (1960) and Parsonage \& Pemberton (1967). Parameters for mixed interactions involving nitrogen have been obtained by a procedure proposed by Giglio (1969).

(b) The symbolic addition method (Karle \& Karle, 1965) was applied. The computer program used was MAGIC (Fleischer, Stone \& Dewar, 1970). The positions of the heavier atoms in the structure were found from an $E$ map based on 60 reflexions.

A full-matrix least-squares refinement of positional and thermal parameters was carried out with a modification of the program $O R F L S$. The function minimized was $\sum w\left(\left|F_{o}\right|-s\left|F_{c}\right|\right)^{2}$, where the summation extends over all reflexions with intensity greater than twice their standard deviation, $s$ is a scaling factor, $\left|F_{o}\right|$ the observed structure factor and $F_{c}$ the calculated structure factor. The weight, $w$, for each reflexion was taken to be $w^{\prime}=\sigma^{-2}$, where $\sigma$ is the estimated standard deviation of the structure factor. $\sigma$ was taken to be $\sigma=2 S+0.01\left|F_{o}\right|$, where $S$ is the standard deviation in $\left|F_{o}\right|$ due to counting statistics. Atomic scattering facfors for carbon and nitrogen were calculated from accurate atomic wavefunctions (Clementi, 1965; Harkema, 1971). The scattering factor for hydrogen was taken from Stewart, Davidson \& Simpson (1965). In a difference-Fourier map, computed after refinement of positional and anisotropic thermal parameters of the non-hydrogen atoms, all hydrogen atoms could be found. The parameters refined werc the positional and anisotropic thermal parameters of the heavier atoms, and the positions and isotropic temperature factors of the hydrogen atoms.

In the refinement a correction for secondary extinction was included (Larson, 1969). Owing to the small linear absorption coefficient no absorption correction was applied. The final $R$ value obtained is $3.9 \%$.

Observed and calculated structure factors are listed in Table 2.

\section{Structural results and discussion}

In the discussion that follows the structure of phthalazine will be compared with the structures of the 1,5and 2,6-isomers (Brufani et al., 1961, 1966) and the 1,8-isomer (Clearfield, Sims \& Singh, 1972).

The final positional and thermal parameters are given in Table 3. The bond lengths, angles and numbering of the atoms are given in Fig. 1. 
Generally speaking all chemically equivalent bond lengths and bond angles are equal within their standard deviations. There might be, however, a small difference between the $C(6)-C(7)$ bond and the $C(3)-C(8)$ bond.

The molecule is not completely planar, which agrees with the argument of Clearfield, Sims \& Singh (1972),

Table 2. Absolute values of observed and calculated structure factors $(\times 10)$, Mo Ka data



Table 3. Atomic parameters for 2,3-diazanaphthalene

Positional parameters are expressed as fractions of cell edges. The anisotropic temperature factor used was $\exp \left[-2 \pi^{2}\left(h^{2} a^{* 2} U_{11}+k^{2} b^{* 2} U_{22}+l^{2} c^{* 2} U_{33}+2 h k a^{*} b^{*} U_{12}+2 h l a^{*} c^{*} U_{13}+2 k l b^{*} c^{*} U_{23}\right)\right]$.

The isotropic temperature factor was $\exp \left(-8 \pi^{2} U \sin ^{2} \theta / \lambda^{2}\right)$. All $U$ values are given in $\AA^{2}$. Standard deviations in the last digits are shown in parentheses. The positional parameters are $\times 10^{4}$ (for the hydrogen atoms: $\times 10^{3}$ ). The thermal parameters for nonhydrogen atoms are $\times 10^{3}$.

\begin{tabular}{|c|c|c|c|c|c|c|c|c|c|}
\hline & $x / a$ & $y / b$ & $z / c$ & $U_{11}$ & $U_{22}$ & $U_{33}$ & $U_{12}$ & $U_{13}$ & $U_{23}$ \\
\hline$N(1)$ & $2755(1)$ & $3388(2)$ & $5820(2)$ & $75(2)$ & $108(1)$ & 80 (1) & $-11(1)$ & $13(1)$ & $7(1)$ \\
\hline$N(2)$ & 2365 (1) & 4329 (2) & 4977 (2) & 57 (1) & $123(2)$ & 80 (1) & -2 (1) & 8 (1) & 1 (1) \\
\hline$C(1)$ & 3641 (2) & $3022(2)$ & $5553(3)$ & 82 (2) & $82(2)$ & 73 (2) & 1 (1) & $8(2)$ & 10 (1) \\
\hline$C(3)$ & $4406(2)$ & $4963(2)$ & 2494 (3) & $58(1)$ & 64 (1) & 72 (1) & 1 (1) & $-5(1)$ & 8 (1) \\
\hline $\mathrm{C}(4)$ & $5331(2)$ & $4556(2)$ & $2262(2)$ & 56 (1) & 78 (1) & $69(2)$ & $-9(1)$ & $5(1)$ & $-1(1)$ \\
\hline$C(5)$ & 5741 (1) & $3621(2)$ & $3117(3)$ & 52 (1) & 81 (2) & 74 (2) & $5(1)$ & 0 (1) & $-13(1)$ \\
\hline C(6) & $5216(2)$ & $3102(2)$ & 4204 (3) & 71 (2) & $68(2)$ & 69 (2) & $16(1)$ & $-10(1)$ & $-1(1)$ \\
\hline$C(7)$ & 4252 (2) & $3502(2)$ & 4464 (2) & 58 (1) & $58(2)$ & 55 (2) & $-1(1)$ & $-2(1)$ & $-5(1)$ \\
\hline $\mathrm{C}(8)$ & 3858 (1) & $4441(2)$ & $3610(2)$ & 44 (1) & 60 (1) & $56(2)$ & $-1(1)$ & $-4(1)$ & $-5(1)$ \\
\hline $\mathbf{H}(1)$ & $385(2)$ & $237(2)$ & $619(2)$ & $0 \cdot 10$ (1) & & & & & \\
\hline $\mathrm{H}(2)$ & $263(2)$ & $546(2)$ & 351 (3) & 0.08 (1) & & & & & \\
\hline $\mathrm{H}(3)$ & $415(2)$ & 557 (2) & $195(2)$ & 0.06 (1) & & & & & \\
\hline $\mathrm{H}(4)$ & 569 (2) & 491 (2) & 147 (3) & 0.07 (1) & & & & & \\
\hline $\mathrm{H}(5)$ & $644(2)$ & 333 (2) & 293 (2) & 0.09 (1) & & & & & \\
\hline $\mathrm{H}(6)$ & $545(2)$ & $250(2)$ & 481 (3) & 0.08 (1) & & & & & \\
\hline
\end{tabular}


that non-planarity can be expected when the lone pairs of electrons on the nitrogen atoms are close to each other, which is the case for the present molecule. Displacements of the atoms from the best plane through the carbon and nitrogen atoms are indicated in Table 4.

\section{Table 4. Atomic deviations from the best plane through the heavy atoms of the molecule}

The equation for the best plane is $0.3475 x+0.6947 y+0.6298 z$ $=7 \cdot 205 \AA$; the coefficients of $x, y, z$ are the direction cosines of the normal to the plane; $x, y, z$ are orthogonal coordinates $(\AA)$.

$\begin{array}{lccc}\text { Atom } & \text { Distance }(\AA) & \text { Atom } & \text { Distance }(\AA) \\ \text { C(1) } & -0.009 & \mathrm{C}(5) & +0.005 \\ \mathrm{H}(1) & -0.008 & \mathrm{H}(5) & +0.01 \\ \mathrm{C}(2) & +0.009 & \mathrm{C}(6) & +0.010 \\ \mathrm{H}(2) & +0.10 & \mathrm{H}(6) & +0.04 \\ \mathrm{C}(3) & -0.009 & \mathrm{C}(7) & -0.003 \\ \mathrm{H}(3) & -0.01 & \mathrm{C}(8) & -0.001 \\ \mathrm{C}(4) & -0.004 & \mathrm{~N}(1) & -0.005 \\ \mathrm{H}(4) & -0.04 & \mathrm{~N}(2) & +0.007\end{array}$

The result is qualitatively the same as that obtained for 1,8-diazanaphthalene. The nitrogen atoms are located at either side of the plane. The separation of the nitrogen atoms, measured perpendicularly to the molecular plane, is about $0.01 \AA$. In 1,8-diazanaphthalene this separation is larger $(0.035 \AA)$. The 1,5- and 2,6-isomers are planar (Brufani et al., 1961, 1966) within 0.005 and $0.003 \AA$ respectively, which can be attributed to the large distances between the lone pairs of electrons on the nitrogen atoms. The largest bond angles in phthalazine are those subtended at the carbon atoms adjacent to the nitrogen atoms; this is also true for the isomers. Small bond angles are found at the nitrogen atoms, the smallest being those subtended at

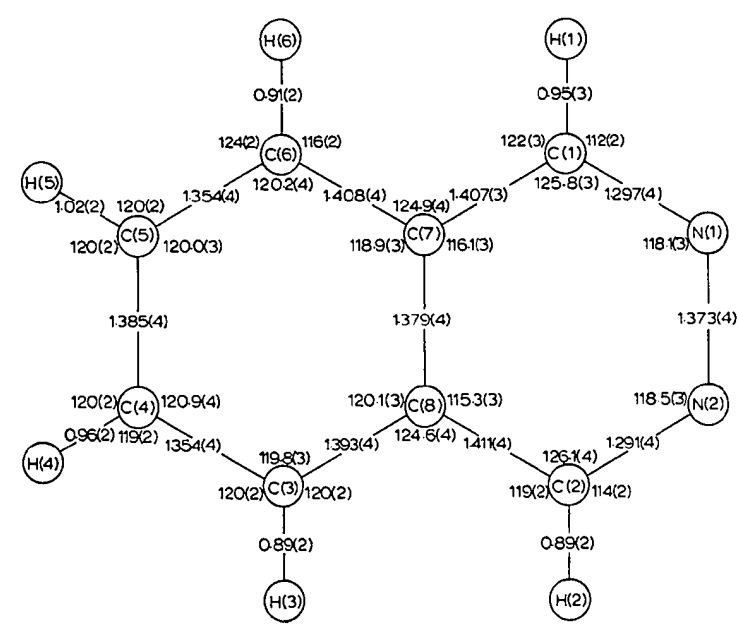

Fig. 1. Bond lengths and bond angles of 2,3-diazanaphthalene. Distances in $\AA$, angles in deg. Standard deviations in the last digits are shown in parentheses.

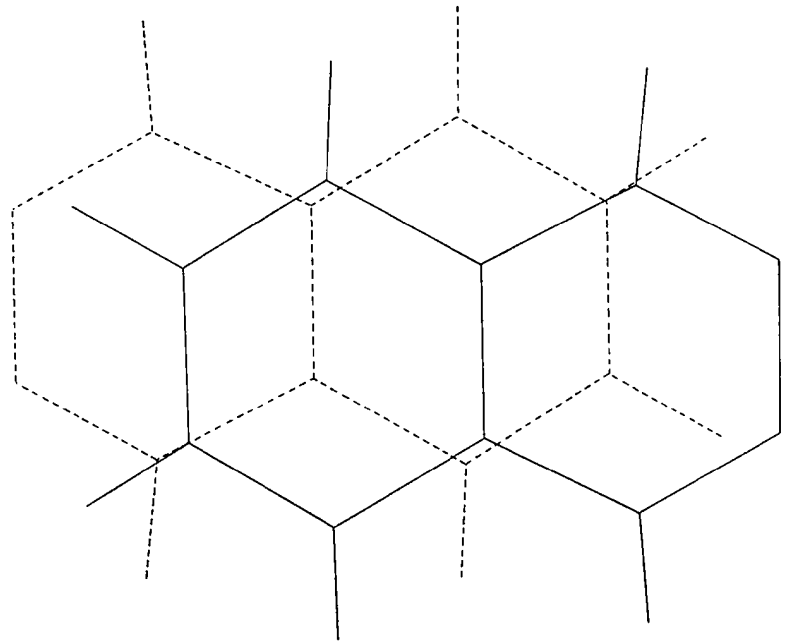

Fig. 2. Line drawing of a pair of parallel molecules. The separation of the molecular planes is $3.53 \AA$.

the bridgehead atoms in the ring containing the nitrogen atoms. This is contrary to the isomers in which the smallest angles are found at the nitrogen atoms.

The molecules are grouped in parallel pairs in the unit cell. Fig. 2 gives a line drawing which shows how the molecules of a parallel pair are arranged with respect to each other. The nitrogen atoms of each molecule point in opposite directions so as to minimize

Table 5. Intermolecular contacts $(\AA)$ within $0 \cdot 2$ A greater than the sum of the relevant van der Waals radii (Kitaigorodsky, 1961)

The reference molecule is at $(x, y, z)$; the translated atom is listed second.

To the molecule at $\left(\frac{1}{2}+x, \frac{1}{2}-y, 1-z\right)$

$$
\mathrm{H}(5)-\mathrm{N}(1) \quad 2 \cdot 80
$$

To the molecule at $\left(1-x, \frac{1}{2}+y, \frac{1}{2}-z\right)$

$$
\mathrm{C}(3)-\mathrm{C}(6) \quad 3 \cdot 70
$$

To the molecule at $\left(\frac{1}{2}-x, 1-y, \frac{1}{2}+z\right)$

$$
\begin{array}{ll}
\mathrm{N}(2)-\mathrm{H}(3) & 2 \cdot 76 \\
\mathrm{~N}(2)-\mathrm{C}(3) & 3 \cdot 45
\end{array}
$$

To the molecule at $(1-x, 1-y, 1-z)$

$\begin{array}{llll}\mathrm{C}(1)-\mathrm{C}(4) & 3.55 & \mathrm{C}(4)-\mathrm{C}(7) & 3 \cdot 71 \\ \mathrm{C}(2)-\mathrm{C}(5) & 3.69 & \mathrm{C}(5)-\mathrm{C}(8) & 3 \cdot 70 \\ \mathrm{C}(3)-\mathrm{C}(6) & 3.72 & \mathrm{C}(5)-\mathrm{C}(7) & 3 \cdot 77 \\ \mathrm{C}(3)-\mathrm{C}(7) & 3.73 & \mathrm{C}(6)-\mathrm{C}(8) & 3 \cdot 52\end{array}$

To the molecule at $\left(x, \frac{1}{2}-y, \frac{1}{2}+z\right)$

$$
\begin{array}{llll}
\mathrm{C}(1)-\mathrm{C}(3) & 3.77 & \mathrm{H}(1)-\mathrm{C}(4) & 3.04 \\
\mathrm{H}(1)-\mathrm{C}(3) & 2.85 & \mathrm{H}(6)-\mathrm{C}(4) & 3.15
\end{array}
$$$$
\mathrm{H}(1)-\mathrm{C}(8) \quad 2.95
$$

To the molecule at $\left(\frac{1}{2}+x, y, \frac{1}{2}-z\right)$

$\begin{array}{llll}\mathrm{C}(4)-\mathrm{N}(2) & 3.48 & \mathrm{H}(4)-\mathrm{N}(2) & 2.72 \\ \mathrm{C}(4)-\mathrm{C}(2) & 3.69 & \mathrm{H}(4)-\mathrm{C}(2) & 3.04 \\ \mathrm{C}(5)-\mathrm{C}(2) & 3.73 & \mathrm{H}(5)-\mathrm{C}(2) & 3.07\end{array}$



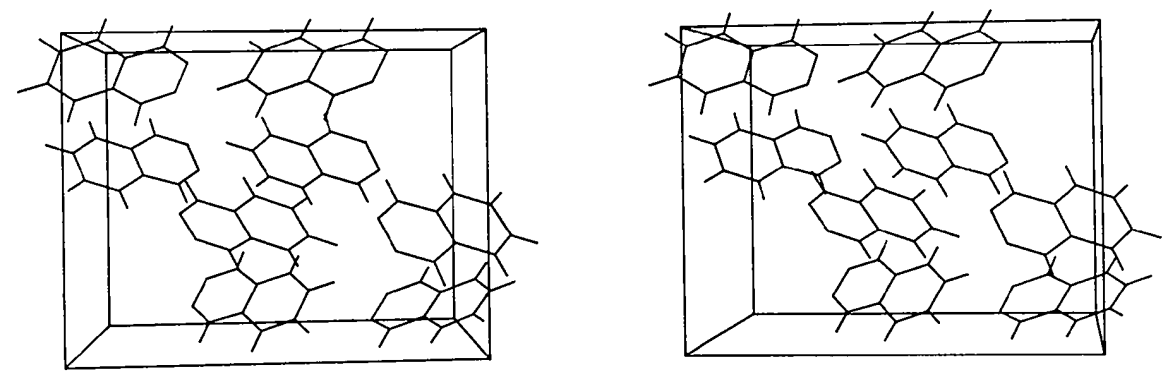

Fig. 3. Stereoscopic pair showing the molecular packing of phthalazine.

electrostatic repulsive effects. In Table 5 the intermolecular contacts are listed. A contact is assumed when the separation between the atomic centres is within a limit of $0 \cdot 2 \AA$ greater than the sum of the relevant van der Waals radii (Kitaigorodsky, 1961). The values of these radii are $R_{\mathrm{H}}=1 \cdot 17, R_{\mathrm{C}}=1.80$ and $R_{\mathrm{N}}=1.57 \AA$. Most contacts occur between the two molecules of a parallel pair; there exist, however, contacts only between the carbon atoms of these molecules. The separation between the molecular planes of a parallel pair amounts $3.53 \AA$, which is slightly more than the separation of the layers in graphite $(3.35 \AA)$, and compares well with the separation of molecular planes of related molecules. A stereoscopic view of the packing is given in Fig. 3.

\section{References}

Bartell, L. (1960). J. Chem. Phys. 32, 827.

Brufani, M., Duranti, D., Giacomello, G. \& Zambonelli, L. (1961). Gazz. Chim. Ital. 91, 287.

Brufani, M., Fedeli, W., Giacomello, G., Riccieri, F. M. \& Vaciago, A. (1966). Atti Accad. Nazl. Lincei Rend. Classe Sci. Fis. Mat. Nat. 40, 187.
Busing, W. R., Martin, K. O. \& LeVy, H. A. (1962). ORFLS. Report ORNL-TM-305. Oak Ridge National Laboratory, Oak Ridge, Tennessee, U.S.A.

Clearfield, A., Sims, M. J. \& Singh, P. (1972). Acta Cryst. B28, 350.

Clementi, E. (1965). IBM Res. Dev. 9, 2.

Fleischer, E. B., Stone, A. L. \& Dewar, R. B. K. (1966). MAGIC. Multiphase Automatic Generation from Intensities in Centric Crystals. Fortran Program. University of Chicago.

Giglio, E. (1969). Nature, Lond. 222, 339.

Ham, D. M. W. van den, Du Sart, J. J. \& van Der Meer, D. (1971). Mol. Phys. 21, 3175.

HAM, D. M. W. VAN DEN \& VAN DER MeER, D. (1972). Chem. Phys. Lett. 12, 447.

HaRkema, S. (1971). Thesis. Twente University of Technology, Enschede, The Netherlands.

Kitaigorodsky, A. I. (1961). Organic Chemical Crystallography. New York: Consultants Bureau.

Karle, J. \& Karle, I. L. (1966). Acta Cryst. $21,849$.

LARson, A. C. (1969). Crystallographic Computing. Edited by F. R. AHMED, p. 291-294. Copenhagen: Munksgaard.

Parsonage, N. G. \& Pemberton, R. C. (1967). Trans. Faraday Soc. 63, 311.

Stewart, R. F., Davidson, E. R. \& Simpson, W. T. (1965). J. Chem. Phys. 42, 3175.

Williams, D. E. (1969). Acta Cryst. A25, 464. 